\title{
Total, insoluble and soluble dietary fibre intake in relation to blood pressure: the INTERMAP Study
}

\author{
Ghadeer S. Aljuraiban ${ }^{1}$, Linda M. O. Griep ${ }^{1}$, Queenie Chan ${ }^{1}$, Martha L. Daviglus ${ }^{2}$, Jeremiah Stamler ${ }^{2}$, \\ Linda Van Horn ${ }^{2}$, Paul Elliott ${ }^{1}$ and Gary S. Frost ${ }^{3 *}$ \\ ${ }^{1}$ Department of Epidemiology and Biostatistics, School of Public Health, MRC-PHE Centre for Environment and Health, \\ Imperial College London, London W2 1PG, UK \\ ${ }^{2}$ Department of Preventive Medicine, Feinberg School of Medicine, Northwestern University, Chicago, IL 60208, USA \\ ${ }^{3}$ Nutrition and Dietetic Research Group, Imperial College London, London W2 1PG, UK
}

(Submitted 26 March 2015 - Final revision received 11 June 2015 - Accepted 14 July 2015 - First published online 2 September 2015)

\section{Abstract}

Prospective cohort studies have shown inverse associations between fibre intake and CVD, possibly mediated by blood pressure (BP). However, little is known about the impact of types of fibre on BP. We examined cross-sectional associations with BP of total, insoluble and soluble fibre intakes. Data were used from the INTERnational study on MAcro/micronutrients and blood Pressure (INTERMAP) study, including 2195 men and women aged between 40 and 59 years from the USA. During four visits, eight BP, four $24 \mathrm{~h}$ dietary recalls and two $24 \mathrm{~h}$ urine samples were collected. Linear regression models adjusted for lifestyle and dietary confounders to estimate BP differences per $2 \mathrm{sD}$ higher intakes of total and individual types of fibre were calculated. After multivariable adjustment, total fibre intake higher by $6 \cdot 8 \mathrm{~g} / 4184 \mathrm{~kJ}$ $(6 \cdot 8 \mathrm{~g} / 1000 \mathrm{kcal})$ was associated with a $1.69 \mathrm{mmHg}$ lower systolic blood pressure (SBP; $95 \% \mathrm{CI}-2 \cdot 97,-0 \cdot 41)$ and attenuated to $-1 \cdot 01 \mathrm{mmHg}$ (95\% CI $-2.35,0.34)$ after adjustment for urinary K. Insoluble fibre intake higher by $4.6 \mathrm{~g} / 4184 \mathrm{~kJ}(4.6 \mathrm{~g} / 1000 \mathrm{kcal})$ was associated with a $1.81 \mathrm{mmHg}$ lower SBP (95\% CI -3.65, 0.04), additionally adjusted for soluble fibre and urinary K excretion, whereas soluble fibre was not associated with BP. Raw fruit was the main source of total and insoluble fibre, followed by whole grains and vegetables. In conclusion, higher intakes of fibre, especially insoluble, may contribute to lower BP, independent of nutrients associated with higher intakes of fibre-rich foods.

Key words: Dietary fibre: Insoluble fibre: Soluble fibre: Blood pressure

High blood pressure (BP) is a major independent risk factor for $\mathrm{CVD}^{(1)}$. Meta-analyses of prospective cohort studies have shown that higher intake of total dietary fibre is associated with a lower risk of fatal and non-fatal coronary events ${ }^{(2,3)}$. Reported cross-sectional findings of total fibre intake and BP, however, were inconsistent: some showed inverse associations ${ }^{(4-6)}$, whereas others observed no association ${ }^{(7,8)}$. The limited available prospective cohort studies found inverse relations between total fibre intake and $\mathrm{BP}$ rise ${ }^{(9)}$, or risk of hypertension ${ }^{(4,5)}$. Methodological limitations of these studies include validity of dietary assessment methods ${ }^{(4-6,8)}$, absent or limited adjustment for dietary and other lifestyle confounders ${ }^{(6,8,10)}$, substitution of fibre supplements rather than dietary fibre sources ${ }^{(11,12)}$ and inadequate frequency of BP measurement ${ }^{(6-8)}$. Meta-analyses of randomised controlled intervention studies showed that fibre supplementation (average dose, $11.5 \mathrm{~g} / \mathrm{d}$ ) did not significantly reduce $\mathrm{BP}^{(11,12)}$, but significant $\mathrm{BP}$-lowering effects were found in hypertensive participants ${ }^{(12)}$. It has been suggested that the mechanism by which higher dietary fibre intakes may lower BP is attributed to enhanced insulin sensitivity that may improve endothelial function and other CVD risk factors ${ }^{(11)}$. The potential effect of insoluble fibre on BP has been less thoroughly investigated. Soluble fibre may have a favourable effect on BP by lowering postprandial glucose responses and LDLcholesterol levels, stimulating the absorption of minerals in the gastrointestinal system, and reducing body weight ${ }^{(11,12)}$. Inconsistent findings on the effect of dietary fibre on BP may relate to differences in study design ${ }^{(13-17)}$ : BP responses to fibre intake may depend on type (insoluble or soluble) or dose of fibre, and whether supplemental fibre or high-fibre dietary sources were consumed (e.g. whole-grain bread) ${ }^{(11)}$. To our knowledge, only one study examined cross-sectional associations between types of fibre and CVD risk factors. The results showed significant lower risks of hypertension for total and insoluble fibre intakes, but not for soluble fibre intake ${ }^{(18)}$.

In the present study, we investigated cross-sectional relations to systolic blood pressure (SBP) and diastolic blood pressure (DBP) of total dietary fibre and its components among the 2195

Abbreviations: BP, blood pressure; DBP, diastolic blood pressure; SBP, systolic blood pressure.

* Corresponding author: Professor G. S. Frost, email g.frost@imperial.ac.uk 
participants of the INTERMAP study in the USA, using highquality dietary data from four multipass $24 \mathrm{~h}$ dietary recalls, eight BP measurements and regression models adjusted extensively for dietary and lifestyle factors.

\section{Methods \\ Population}

The INTERnational study on MAcro/micronutrients and blood Pressure (INTERMAP) included 4680 men and women aged between 40 and 59 years. Participants were randomly recruited from community and workforce populations (seventeen population samples) in Japan, the People's Republic of China, the UK and the USA ${ }^{(19)}$. Between 1996 and 1999, participants attended four clinic visits, two on consecutive days and two on consecutive days approximately 3 weeks later. Dietary and nondietary data collection underwent extensive quality control, including national and international checks to ensure completeness and accuracy. This study was approved by institutional ethics committees at all sites. Each participant consented in writing.

Information on types of fibre (insoluble, soluble) is only available for the US samples; therefore, we analysed data on 2195 participants (1103 men and 1092 women) from eight US population samples. Of 2281 US participants initially surveyed, individuals were excluded when they did not attend all four visits or had incomplete/missing data, presented unreliable dietary data, or unavailable $24 \mathrm{~h}$ urine samples $(n 65)$ or had extreme total energy intake from any $24 \mathrm{~h}$ recall of $<2092 \mathrm{~kJ} / \mathrm{d}$ $(<500 \mathrm{kcal} / \mathrm{d})$ or $>20920 \mathrm{~kJ} / \mathrm{d}(>5000 \mathrm{kcal} / \mathrm{d})$ for women and $<2092 \mathrm{~kJ} / \mathrm{d}(<500 \mathrm{kcal} / \mathrm{d})$ or $>33472 \mathrm{~kJ} / \mathrm{d}$ (>8000 kcal/d) for men ( $n$ 21).

\section{Clinic visits}

Visits were randomly spread over the year. On each of the four visits, BP was measured twice and $24 \mathrm{~h}$ dietary recalls were performed once. Two-timed $24 \mathrm{~h}$ urine collections were obtained on the second and fourth visits. Height and body weight were measured twice on the first and third visits. On the first visit, a health history questionnaire was completed to collect information on medical history, medication intake, smoking and physical activity. On each of the four visits, participants provided information on their vitamin and supplement intakes.

\section{Dietary assessment}

Four $24 \mathrm{~h}$ dietary recalls were collected from each participant using a standardised multipass method reported in detail elsewhere $^{(20)}$. In brief, trained interviewers collected in-depth data on all foods, beverages and supplements consumed in the past $24 \mathrm{~h}$ in face-to-face interviews. In the USA, dietary data were transferred to software (the Nutrition Data System (NDS), Nutrition Coordinating Centre (NCC), version 2.91, University of Minnesota) for on-screen coding during an interview ${ }^{(20)}$. Daily nutrient intakes were obtained using the NDS for research, version $4.01^{(20,21)}$. For quality control assessment, dietary recall data were compared with urinary excretion data. Pearson's partial correlation coefficients adjusted for sample and sex between dietary and urinary total protein, $\mathrm{Na}$ and $\mathrm{K}$ were 0.52 , 0.46 and 0.58 , respectively ${ }^{(20)}$.

According to the NCC, insoluble dietary fibre includes cellulose, non-cellulose insoluble polysaccharides (mostly hemicellulose), lignin and some resistant starch. Soluble dietary fibre includes pectins, gums, muscilages and non-cellulose soluble polysaccharides (some hemicelluloses). We identified all sources of dietary fibre reported by participants: whole grains (bread and bread products, brown rice and pasta), refined grains (bread and bread products, pasta and rice), cereal products (ready-to-eat cereal, cooked cereal and granola bars), legumes, vegetables (cooked and raw vegetables), raw fruits, dried fruits, nuts and seeds.

The reliability of fibre intake for individuals was estimated using the following formula: $1 /[1+($ ratio/2) $] \times 100$. The ratio is intra-individual variance divided by the inter-individual variance, estimated separately by gender, and combined. The averages of the first two and second two visits were used to account for higher correlation between dietary intakes on consecutive days. This gives an indication of the effect of random error (day-to-day variability) on the associations with $\mathrm{BP}^{(22)}$.

\section{Measurement of blood pressure}

SBP and DBP were measured by trained staff using a randomzero sphygmomanometer. Participants refrained from food, drinks, smoking and physical activity for $30 \mathrm{~min}$. They were seated in a quiet room for at least $5 \mathrm{~min}$, their bladders were emptied and their feet were placed flat on the floor. BP was measured twice on the right arm at each of the four clinic visits, using first and fifth Korotkoff sounds, totalling eight BP readings.

\section{Other variables}

During two visits, weight and height measurements without shoes or heavy clothing were collected four times and the BMI $\left(\mathrm{kg} / \mathrm{m}^{2}\right)$ was calculated. Urinary $\mathrm{Na}, \mathrm{Mg}$, Ca and $\mathrm{K}$ levels were measured from two-timed $24 \mathrm{~h}$ urinary samples collected between consecutive visits. Data on lifestyle factors were assessed using interviewer-guided questionnaires on smoking, education, hours of physical activity, adherence to a weightreduction diet, use of antihypertensive and lipid-lowering drugs, individual and family history of CVD and diabetes mellitus and daily alcohol intake during the past $7 \mathrm{~d}$.

\section{Statistical methods}

Statistical analyses were conducted using SAS software version 9.3 (SAS Institute Inc.). Dietary data were energy-adjusted using the nutrient density method. Dietary intake was estimated as a mean of the four dietary recalls. The mean value of eight BP measurements was used in the analysis. Urinary data were averaged across the two $24 \mathrm{~h}$ urinary collections ${ }^{(23)}$. Isoenergitic models were adjusted for total protein, fat and sugar (\% energy) to enable assessment of the independent relation of fibre intake $(\mathrm{g} / 4184 \mathrm{~kJ}(\mathrm{~g} / 1000 \mathrm{kcal}))$ with $\mathrm{BP}$, including control for total energy intake ${ }^{(23)}$. 
Baseline characteristics of US participants and $P_{\text {trend }}$ across quartiles of total fibre intake were calculated using a generalised linear model adjusted for age, sex, total energy intake $(\mathrm{kJ} / 24 \mathrm{~h}(\mathrm{kcal} / 24 \mathrm{~h}))$, total protein (\% energy), total fat (\% energy) and population sample.

Multivariable linear regression analyses were used to examine associations between total, insoluble and soluble fibre (per $2 \mathrm{sD} 6 \cdot 8,4 \cdot 6$, and $2 \cdot 2 \mathrm{~g} / 4184 \mathrm{~kJ}(2 \cdot 2 \mathrm{~g} / 1000 \mathrm{kcal})$, respectively) and BP, including the total US cohort ( $n$ 2195). In addition, we also applied linear regression analyses in a subcohort, excluding participants with hypertension and use of antihypertensive drugs ( $n$ 1477). Three models were used, adjusted extensively for lifestyle and dietary factors, with and without adjustment for BMI. Potential confounders of the association of fibre intake with BP were selected from the literature. Model 1 was adjusted for age (years), sex (male or female), total energy intake $(\mathrm{kJ} / 24 \mathrm{~h}(\mathrm{kcal} / 24 \mathrm{~h}))$, total protein (\% energy), total fat (\% energy) and population sample (i.e. centre). Model 2 was adjusted for variables in model 1 plus adherence to a special diet (yes or no), physical activity during leisure time (a lot, moderate, little or none), dietary supplement use (yes or no), smoking (never, former or current), years of education (years completed), alcohol intake $(\mathrm{g} / 24 \mathrm{~h})$, history of CVD or diabetes mellitus (yes or no), family history of CVD (yes or no). Model 3 was fully adjusted, including variables in model 2 plus $24 \mathrm{~h}$ urinary excretion of $\mathrm{Na}(\mathrm{mmol} / 24 \mathrm{~h})$. In addition, we sequentially investigated the influence of nutrients strongly related to fibre intake on the association, including $24 \mathrm{~h}$ urinary excretion $(\mathrm{mmol} / 24 \mathrm{~h})$ of $\mathrm{Mg}$, $\mathrm{Ca}$ and $\mathrm{K}(\mathrm{mmol} / 24 \mathrm{~h})$. No missing values were observed.

Analyses were repeated for two sub-cohorts with characteristics that may bias relationships between fibre intake and BP: a sub-cohort of non-hypertensive participants ( $n$ 1421) additionally excluding participants with elevated SBP $(\geq 140 \mathrm{mmHg})$ or DBP ( $\geq 90 \mathrm{mmHg}$ ); and a sub-cohort free of major chronic diseases ( $n$ 1262) additionally excluding those diagnosed with CVD or diabetes.

Interactions by age and sex were examined by inclusion of separate terms in each regression model; there was no evidence for interaction. Two-tailed probability values $(P<0.05)$ were considered statistically significant.

\section{Results}

\section{Descriptive statistics}

Across quartiles of total fibre intake, participants in the highest quartile of total fibre intake were older, had more years of education, had greater intakes of total protein, vegetables, raw fruits and dried fruits, had lower levels of BMI and BP and lower intakes of alcohol, total sugar, total fat and refined grains compared with those in the lowest quartile (Table 1). The predominant dietary source of total and insoluble fibre was raw fruits ( 54 and $57 \%$ ), followed by refined grains (16 and 14\%), vegetables (15 and $12 \%$ ) and whole-grain cereal products (12 and $13 \%)$. For soluble fibre, dietary sources were raw fruits (48\%), vegetables (21\%), refined grains (19\%) and whole grains and cereal products $(9 \%)$. The reliability estimate for total fibre intake $(\mathrm{g} / \mathrm{d})$ was $82 \%$ overall, $80 \%$ in men and $83 \%$ in women.

\section{Associations of total fibre with blood pressure}

After adjustment for lifestyle factors and BMI, total dietary fibre intake higher by $2 \mathrm{sD}(6.8 \mathrm{~g} / 4184 \mathrm{~kJ}(6.8 \mathrm{~g} / 1000 \mathrm{kcal}))$ was associated with a SBP lower by $1.69 \mathrm{mmHg}(95 \% \mathrm{CI}-2.97$, -0.41) (Table 2). Additional adjustment for urinary K excretion attenuated this association and did not remain statistically significant $(-1.01 \mathrm{mmHg}$; $95 \% \mathrm{CI}-2 \cdot 35,0.34)$.

\section{Associations of types of fibre with blood pressure}

Insoluble fibre intake higher by $2 \mathrm{sD}(4.6 \mathrm{~g} / 4184 \mathrm{~kJ}(4.6 \mathrm{~g} / 1000$ kcal)) was associated with a $2.07 \mathrm{mmHg}$ lower SBP (95\% CI $-3.92,-0.23)$, after adjustment for lifestyle factors, BMI and soluble fibre (Table 2). Adjustment for urinary $\mathrm{K}$ attenuated the association and did not remain statistically significant $(-1.81$ mmHg; 95\% CI -3.65, 0.04). Insoluble fibre intake was also inversely associated with DBP $(-1.32 \mathrm{mmHg}$; $95 \%$ CI $-2 \cdot 60$, $-0 \cdot 04)$; this association was also attenuated with adjustment for urinary $\mathrm{Mg}(-1.23 \mathrm{mmHg}$; $95 \% \mathrm{CI}-2.51,0.06)$. Soluble fibre intake was not associated with SBP or DBP.

Associations of fibre intakes with blood pressure, excluding participants with hypertension and use of antihypertensive drugs

We repeated the regression analyses in a cohort, excluding participants with hypertension and use of antihypertensive drugs (Table 3). The results showed that total dietary fibre intake higher by $2 \mathrm{sD}(6.9 \mathrm{~g} / 4184 \mathrm{~kJ}(6.9 \mathrm{~g} / 1000 \mathrm{kcal}))$ was associated with a SBP lower by $1.85 \mathrm{mmHg}(95 \% \mathrm{CI}-3 \cdot 13$, -0.57). The inverse association between total fibre intake and SBP was independent of urinary $\mathrm{K}$ excretion $(-1.69 \mathrm{mmHg}$; $95 \%$ CI $-3 \cdot 04,-0 \cdot 34)$.

Insoluble fibre intake higher by $2 \mathrm{sD} \quad(4.8 \mathrm{~g} / 4184 \mathrm{~kJ}$ $(4.8 \mathrm{~g} / 1000 \mathrm{kcal}))$ was associated with a $2.52 \mathrm{mmHg}$ lower SBP (95\% CI $-4.42,-0.63$ ), after adjustment for lifestyle factors, BMI and soluble fibre. The association remained significant after adjustment for urinary $\mathrm{K}(-2.48 \mathrm{mmHg} ; 95 \% \mathrm{CI}-4.38,-0.58)$. Soluble fibre intake was not associated with SBP or DBP, as in the main analyses.

\section{Associations of fibre intakes with blood pressure in sub-cohorts}

We repeated the regression analyses in other sub-cohorts, excluding participants with characteristics that may bias associations between fibre intake and BP (online Supplementary Table S2): a sub-cohort of non-hypertensive participants and a sub-cohort free of major chronic diseases (additionally excluding those with CVD and diabetes). Associations between total, insoluble fibre intake and BP in the two sub-cohorts were comparable with those from the main analyses. Although the association between SBP and insoluble fibre was slightly attenuated in non- 
Table 1. Baseline characteristics of US INTERMAP participants by quartiles of total fibre intake (Mean values with their standard errors; percentages; $n 2195)^{\star}$

\begin{tabular}{|c|c|c|c|c|c|c|c|c|c|}
\hline \multirow[b]{2}{*}{ Variable } & \multicolumn{2}{|c|}{ Q1 } & \multicolumn{2}{|c|}{ Q2 } & \multicolumn{2}{|c|}{ Q3 } & \multicolumn{2}{|c|}{ Q4 } & \multirow[b]{2}{*}{$P_{\text {trend }}$} \\
\hline & Mean & SE & Mean & SE & Mean & SE & Mean & SE & \\
\hline$n$ & \multicolumn{2}{|c|}{548} & \multicolumn{2}{|c|}{549} & \multicolumn{2}{|c|}{549} & \multicolumn{2}{|c|}{549} & \\
\hline Men (\%) & \multicolumn{2}{|c|}{50} & \multicolumn{2}{|c|}{50} & \multicolumn{2}{|c|}{50} & \multicolumn{2}{|c|}{50} & \\
\hline Total fibre $(\mathrm{g} / 4184 \mathrm{~kJ}(\mathrm{~g} / 1000 \mathrm{kcal}))$ & 5 & 0.1 & 8 & 0.1 & 9 & 0.1 & 12 & 0.1 & $<0.0001$ \\
\hline Insoluble fibre $(\mathrm{g} / 4184 \mathrm{~kJ}(\mathrm{~g} / 1000 \mathrm{kcal}))$ & 3 & 0.1 & 5 & 0.1 & 6 & 0.1 & 8 & 0.1 & $<0.0001$ \\
\hline Soluble fibre (g/4184 kJ (g/1000 kcal)) & 2 & 0.03 & 3 & 0.03 & 3 & 0.03 & 4 & 0.03 & $<0.0001$ \\
\hline Age (years) & 48 & 0.2 & 49 & 0.2 & 49 & 0.2 & 50 & 0.2 & $<0.0001$ \\
\hline Education (years) & 14 & 0.1 & 15 & 0.1 & 15 & 0.1 & 15 & 0.1 & $<0.0001$ \\
\hline Current smokers (\%) & \multicolumn{2}{|c|}{26} & \multicolumn{2}{|c|}{19} & \multicolumn{2}{|c|}{$13^{0 \cdot 1}$} & \multicolumn{2}{|c|}{$9^{0.1}$} & $<0.0001$ \\
\hline Alcohol intake $(\mathrm{g} / \mathrm{d})$ & 7 & 1 & 8 & 1 & 8 & 1 & 5 & 1 & $<0.0001$ \\
\hline Engagement in moderate and heavy physical activity $(\mathrm{h} / \mathrm{d})$ & 4 & 0.1 & 3 & 0.1 & 3 & 0.1 & 3 & 0.1 & 0.12 \\
\hline Taking dietary supplements (\%) & \multicolumn{2}{|c|}{40} & \multicolumn{2}{|c|}{52} & \multicolumn{2}{|c|}{56} & \multicolumn{2}{|c|}{60} & $<0.0001$ \\
\hline BMI $\left(\mathrm{kg} / \mathrm{m}^{2}\right)$ & $30 \cdot 1$ & 0.3 & $29 \cdot 0$ & 0.3 & 28.5 & 0.2 & $28 \cdot 1$ & 0.3 & $<0.0001$ \\
\hline Systolic BP (mmHg) & $120 \cdot 6$ & 0.6 & $119 \cdot 2$ & 0.6 & 118.4 & 0.6 & $116 \cdot 3$ & 0.6 & $<0.0001$ \\
\hline Diastolic BP (mmHg) & 74.4 & 0.4 & 73.7 & 0.4 & 73.3 & 0.4 & $72 \cdot 2$ & 0.4 & 0.003 \\
\hline History of CVD or diabetes mellitus (\%) & \multicolumn{2}{|c|}{14} & \multicolumn{2}{|c|}{18} & \multicolumn{2}{|c|}{15} & & & 0.53 \\
\hline Use of antihypertensive and/or CVD treatment (\%) & & & & & & & & & 0.17 \\
\hline Family history of hypertension (\%) & & & & & & & & & 0.32 \\
\hline Adhering to energy-restricted diet (\%) & & 5 & & 5 & & & & & $<0.0001$ \\
\hline Total energy intake $(\mathrm{kJ} / 24 \mathrm{~h})$ & 9874.2 & $100 \cdot 4$ & 9531.2 & $100 \cdot 4$ & 9342.9 & $100 \cdot 4$ & 8778.8 & 104.6 & $<0.0001$ \\
\hline Total energy intake (kcal/24 h) & 2360 & 24 & 2278 & 24 & 2233 & 24 & 2098 & 25 & $<0.0001$ \\
\hline Sugar (\% energy) & 29 & 0.3 & 27 & 0.3 & 26 & 0.3 & 26 & 0.3 & $<0.0001$ \\
\hline Total protein (\% energy) & 15 & 0.1 & 15 & 0.1 & 16 & 0.1 & 16 & 0.1 & $<0.0001$ \\
\hline Total fat (\% energy) & 35 & 0.3 & 34 & 0.3 & 33 & 0.3 & 29 & 0.3 & $<0.0001$ \\
\hline Urinary samples $(\mathrm{mmol} / 24 \mathrm{~h})$ & & & & & & & & & \\
\hline Urinary $\mathrm{Na}$ & $155 \cdot 3$ & $2 \cdot 3$ & 163 & $2 \cdot 2$ & $164 \cdot 8$ & $2 \cdot 2$ & $167 \cdot 3$ & $2 \cdot 4$ & 0.003 \\
\hline Urinary $\mathrm{Mg}$ & 3.7 & 0.1 & 4 & 0.1 & 4.4 & 0.1 & 4.8 & 0.1 & $<0.0001$ \\
\hline Urinary $\mathrm{Ca}$ & 3.9 & 0.1 & 4 & 0.1 & $4 \cdot 4$ & 0.1 & 4.4 & 0.1 & 0.0003 \\
\hline Urinary $\mathrm{K}$ & $49 \cdot 2$ & 0.8 & 55 & 0.8 & $60 \cdot 8$ & 0.8 & $66 \cdot 0$ & 0.8 & $<0.0001$ \\
\hline Dietary sources ( $\mathrm{g} / 4184 \mathrm{~kJ}(\mathrm{~g} / 1000 \mathrm{kcal}))$ & & & & & & & & & \\
\hline Whole-grain and fibre-rich cereal & 7 & 4 & 5 & 4 & 8 & 4 & 14 & 4 & 0.08 \\
\hline Refined grains & 32 & 1 & 29 & 1 & 30 & 1 & 26 & 1 & 0.01 \\
\hline Legumes & 0.2 & 1 & 0.2 & 1 & 0.2 & 1 & $2 \cdot 3$ & 1 & 0.01 \\
\hline Nuts and seeds & 0.1 & 0.1 & 0.1 & 0.1 & 0.3 & 0.1 & 0.4 & 0.1 & 0.67 \\
\hline Vegetables & 43 & 3 & 55 & 4 & 67 & 4 & 80 & 4 & $<0.0001$ \\
\hline Raw fruit & 25 & 2 & 38 & 2 & 44 & 2 & 55 & 2 & $<0.0001$ \\
\hline Dried fruit & 2 & 1 & 2 & 1 & 3 & 1 & 4 & 1 & 0.004 \\
\hline
\end{tabular}

BP, blood pressure

* The generalised linear model was adjusted for age, sex, total energy ( $\mathrm{kJ} / 24 \mathrm{~h}(\mathrm{kcal} / 24 \mathrm{~h})$ ), total protein (\% energy), total fat (\% energy), total sugar (\% energy) and population sample.

hypertensive participants, it remained significant $(-1.89 \mathrm{mmHg}$; $95 \%$ CI $-3.63,-0.15)$. After further exclusion of participants previously diagnosed with CVD or diabetes, the association between insoluble fibre and SBP did not remain statistically significant. Furthermore, the analyses were repeated, excluding participants who were taking fibre supplements ( $n$ 78). Results were compatible to the main analyses (data not shown).

\section{Discussion}

In this cross-sectional, population-based study of 2195 Americans participating in the INTERMAP Study, a higher intake of total dietary fibre was associated with lower BP; this finding may be attributable to the observed inverse association between insoluble fibre and SBP but not with soluble fibre. The associations between total, insoluble dietary fibre and SBP were attenuated with adjustment for urinary $\mathrm{K}$ levels. Results remained significant with adjustment of BMI, and are therefore independent of BMI influence. In the sub-cohort, excluding participants with hypertension and the use of antihypertensive drugs, the associations between total, insoluble dietary fibre and $\mathrm{BP}$ were independent of nutrients associated with higher intakes of fibre-rich foods, including $\mathrm{K}$.

Previous cross-sectional ${ }^{(4-8,24,25)}$ and prospective ${ }^{(4,5,9)}$ analyses have reported inconsistent findings on the association between total dietary fibre intake and BP. Some studies analysed crosssectionally found inverse associations between total fibre intake and $\mathrm{BP}^{(4-6)}$, and some reported no association ${ }^{(7,8)}$. In prospective cohort studies, inverse relations between total fibre intake and BP change ${ }^{(9)}$, or risk of developing hypertension ${ }^{(4,5)}$, were significant in white men and white women only ${ }^{(5,9)}$ or no longer significant after adjustment for dietary confounders ${ }^{(5)}$. The inconsistent results may be explained by methodological issues and differences. First, in most of the studies, results were based on models that were mainly adjusted for non-dietary confounders $^{(24,25)}$ or included few dietary confounders ${ }^{(6,8,10)}$. Second, for most studies that examined the association of total fibre and BP, the frequency of BP measurements was typically low (one ${ }^{(7)}$ or two ${ }^{(6,8)}$ BP measures) or even based on self-reported data ${ }^{(4,5)}$. Third, most studies calculated fibre intakes 
Table 2. Estimated mean difference in blood pressure associated with 2 SD higher intakes of total fibre, insoluble fibre and soluble fibre in US INTERMAP participants

(Mean differences and $95 \%$ confidence intervals; $n$ 2195) ${ }^{\star}$

\begin{tabular}{|c|c|c|c|c|c|c|c|c|c|c|c|c|}
\hline \multirow[b]{3}{*}{ Model } & \multicolumn{6}{|c|}{$\mathrm{SBP}(\mathrm{mmHg})$} & \multicolumn{6}{|c|}{$\mathrm{DBP}(\mathrm{mmHg})$} \\
\hline & \multicolumn{3}{|c|}{ Not adjusted for BMI } & \multicolumn{3}{|c|}{ Adjusted for BMI } & \multicolumn{3}{|c|}{ Not adjusted for BMI } & \multicolumn{3}{|c|}{ Adjusted for BMI } \\
\hline & Difference & $95 \% \mathrm{Cl}$ & $P$ & Difference & $95 \% \mathrm{Cl}$ & $P$ & Difference & $95 \% \mathrm{Cl}$ & $P$ & Difference & $95 \% \mathrm{Cl}$ & $P$ \\
\hline \multicolumn{13}{|l|}{ Total fibre } \\
\hline Model 1 & -3.45 & $-4 \cdot 74,-2 \cdot 16$ & $<0.0001$ & $-2 \cdot 35$ & $-3 \cdot 58,-1 \cdot 11$ & 0.0002 & $-1 \cdot 80$ & $-2.68,-0.92$ & $<0.0001$ & $-1 \cdot 18$ & $-2.04,-0.33$ & 0.01 \\
\hline Model 2 & $-2 \cdot 88$ & $-4 \cdot 20,-1.55$ & $<0.0001$ & -1.69 & $-2.96,-0.41$ & 0.01 & -1.53 & $-2.43,-0.62$ & 0.001 & -0.85 & $-1.73,0.04$ & 0.06 \\
\hline Model 3 & -2.91 & $-4.23,-1.59$ & $<0.0001$ & -1.69 & $-2.97,-0.41$ & 0.01 & -1.54 & $-2.45,-0.64$ & 0.001 & -0.84 & $-1.73,0.05$ & 0.06 \\
\hline Model 4 & -2.95 & $-4.31,-1.59$ & $<0.0001$ & -1.63 & $-2.94,-0.33$ & 0.01 & -1.48 & $-2.41,-0.56$ & 0.002 & -0.73 & $-1 \cdot 63,0.18$ & 0.12 \\
\hline Model 5 & -2.90 & $-4.22,-1.57$ & $<0.0001$ & -1.73 & $-3.01,-0.45$ & 0.01 & -1.54 & $-2.45,-0.64$ & 0.001 & -0.87 & $-1.76,0.02$ & 0.05 \\
\hline Model 6 & -2.66 & $-4.05,-1.27$ & 0.0002 & -1.01 & $-2.35,0.34$ & 0.14 & -1.37 & $-2 \cdot 32,-0.42$ & 0.01 & -0.42 & $-1.35,0.51$ & 0.38 \\
\hline \multicolumn{13}{|l|}{$\begin{array}{l}\text { Insoluble } \\
\text { fibre† }\end{array}$} \\
\hline Model 1 & -3.56 & $-5.50,-1.62$ & 0.0003 & -2.45 & $-4.30,-0.60$ & 0.01 & $-2 \cdot 23$ & $-3.55,-0.91$ & 0.001 & $-1 \cdot 61$ & $-2.89,-0.33$ & 0.01 \\
\hline Model 2 & $-3 \cdot 19$ & $-5 \cdot 11,-1 \cdot 27$ & 0.001 & -2.07 & $-3.91,-0.23$ & 0.03 & -1.96 & $-3.28,-0.65$ & 0.004 & -1.32 & $-2.60,-0.04$ & 0.04 \\
\hline Model 3 & $-3 \cdot 15$ & $-5.07,-1 \cdot 23$ & 0.001 & $-2 \cdot 07$ & $-3.92,-0.23$ & 0.03 & -1.94 & $-3.26,-0.63$ & 0.004 & $-1 \cdot 32$ & $-2.60,-0.04$ & 0.04 \\
\hline Model 4 & $-3 \cdot 23$ & $-5 \cdot 17,-1 \cdot 29$ & 0.001 & $-2 \cdot 01$ & $-3.87,-0.16$ & 0.03 & -1.92 & $-3.25,-0.60$ & 0.004 & -1.23 & $-2.51,0.06$ & 0.06 \\
\hline Model 5 & $-3 \cdot 15$ & $-5 \cdot 07,-1 \cdot 23$ & 0.001 & -2.05 & $-3.89,-0.20$ & 0.03 & -1.95 & $-3.26,-0.63$ & 0.004 & $-1 \cdot 32$ & $-2.59,-0.04$ & 0.04 \\
\hline Model 6 & $-3 \cdot 10$ & $-5.03,-1.17$ & 0.002 & $-1 \cdot 81$ & $-3.65,0.04$ & 0.06 & -1.90 & $-3.22,-0.58$ & 0.01 & $-1 \cdot 16$ & $-2 \cdot 44,0 \cdot 12$ & 0.08 \\
\hline \multicolumn{13}{|l|}{$\begin{array}{l}\text { Soluble } \\
\text { fibre } \neq\end{array}$} \\
\hline Model 1 & $0 \cdot 10$ & $-1.88,2.09$ & 0.92 & -0.02 & $-1.91,1.86$ & 0.98 & 0.37 & $-0.98,1.72$ & 0.59 & 0.30 & $-1.01,1.72$ & 0.65 \\
\hline Model 2 & 0.42 & $-1.54,2.39$ & 0.67 & 0.42 & $-1 \cdot 46,2 \cdot 30$ & 0.66 & 0.40 & $-0.94,1.75$ & 0.56 & 0.40 & $-0.90,1.70$ & 0.55 \\
\hline Model 3 & 0.32 & $-1 \cdot 64,2 \cdot 28$ & 0.75 & 0.42 & $-1 \cdot 46,2 \cdot 29$ & 0.66 & 0.35 & $-0.99,1.69$ & 0.61 & 0.41 & $-0.90,1.71$ & 0.54 \\
\hline Model 4 & 0.40 & $-1.57,2.37$ & 0.69 & 0.41 & $-1 \cdot 47,2 \cdot 29$ & 0.67 & 0.41 & $-0.94,1.75$ & 0.55 & 0.42 & $-0.89,1 \cdot 72$ & 0.53 \\
\hline Model 5 & 0.36 & $-1 \cdot 60,2 \cdot 32$ & 0.72 & 0.35 & $-1 \cdot 52,2 \cdot 23$ & 0.71 & 0.37 & $-0.97,1.71$ & 0.59 & 0.37 & $-0.94,1.67$ & 0.58 \\
\hline Model 6 & 0.61 & $-1.38,2.59$ & 0.55 & 0.88 & $-1 \cdot 01,2 \cdot 78$ & 0.36 & 0.53 & $-0.83,1.88$ & 0.45 & 0.68 & $-0.63,2.00$ & 0.31 \\
\hline
\end{tabular}

DBP, diastolic blood pressure; SBP, systolic blood pressure.

* 2 sD fibres ( $\mathrm{g} / 4184 \mathrm{~kJ}(\mathrm{~g} / 1000 \mathrm{kcal})$ ) total fibre (6.8); insoluble fibre (4.6); soluble fibre (2.2). Model $1 \mathrm{was}$ adjusted for age, gender, total energy (kJ/24 h (kcal/24 $\mathrm{h})$ ), total protein (\% energy), total fat (\% energy), total sugar (\% energy) and population sample. Model 2 was adjusted as model 1 variables plus adherence to energy-restricted diet, smoking, alcohol intake $(\mathrm{g} / 24 \mathrm{~h})$, hours engaged in moderate and heavy physical activity, dietary supplement use, educational level, CVD or diabetes diagnosis and family history of high blood pressure. Model 3 was adjusted as model 2 plus urinary $\mathrm{Na}$ (mmol/24 h). Model 4 was adjusted as model 3 plus urinary Mg (mmol/24 h). Model 5 was adjusted as model 3 plus urinary calcium (mmol/24 h). Model 6 was adjusted as model 3 plus urinary $\mathrm{K}(\mathrm{mmol} / 24 \mathrm{~h})$.

$\dagger$ Additionally adjusted for soluble fibre (g/4184 kJ (g/1000 kcal)).

$\ddagger$ Additionally adjusted for insoluble fibre $(\mathrm{g} / 4184 \mathrm{~kJ}$ (g/1000 kcal)).

from single ${ }^{(6,8)}$, self-administered food frequency questionnaires $^{(4,5)}$ or, alternatively, single $24 \mathrm{~h}$ dietary recalls ${ }^{(6,7)}$. Our findings were derived from eight averaged BP measurements and four high-quality $24 \mathrm{~h}$ multipass dietary recalls per person collected over four visits. Moreover, we found stronger correlations between dietary and urinary variables from two-timed $24 \mathrm{~h}$ urinary collections in comparison with previously reported values $^{(26)}$. Dietary intakes were also energy-adjusted using the nutrient density method and an isoenergetic analysis that allows for interpretation of the relation of the nutrient composition of the diet with the outcome - that is, $\mathrm{BP}$ - while controlling for total energy intake ${ }^{(23)}$. The availability of urine samples enabled us to adjust multivariate models for objective dietary intake measures, which in most other studies is not available.

The independent association between different types of dietary fibre and BP has been less thoroughly explored. To our knowledge, this is the first report on possible cross-sectional associations between total, insoluble and soluble dietary fibre intakes and BP, measured eight times, using models adjusted extensively for possible dietary and other lifestyle confounders. Previously, a cross-sectional analysis including 5961 middle-aged men and women of the SUVIMAX study reported that participants in the highest quartiles had a lower risk of hypertension of $29 \%$ for total and $32 \%$ for insoluble dietary fibre intakes, with no association reported for soluble fibre intake. The study showed that $5 \mathrm{~g} / \mathrm{d}$ higher total fibre intake was associated with a $12 \%$ lower risk of hypertension ${ }^{(18)}$. Although dietary fibre intakes were estimated by six $24 \mathrm{~h}$ dietary recalls, this study used only one BP measurement. Another limitation is that analyses were not controlled for several confounding factors including family history of CVD or high BP. Our results are also compatible with findings of a recent metaanalysis of twenty-two cohort studies that showed inverse associations between insoluble fibre intake and CVD, with no significant associations for soluble fibre intake, which may be attributed to low soluble fibre intake ${ }^{(27)}$.

BP-lowering effects of fibre have previously been attributed to a variety of factors, including increased nitric oxide release (a vasodilator) ${ }^{(28)}$; improvement in endothelial function by inhibiting $\mathrm{Na}$ absorption ${ }^{(28)}$, although inconclusive ${ }^{(29)}$; improvement of other CVD risk factors ${ }^{(30)}$; and improved insulin sensitivity and hyperglycaemia ${ }^{(31,32)}$.

Participants with diagnosed high BP, CVD or diabetes may have changed their dietary habits after their diagnosis towards a healthier pattern. Moreover, those participants have presumably lower BP levels due to their use of BP-lowering medication, which may distort the relationship between fibre intake and BP level. However, when those participants were excluded, results were consistently inverse. Based on these findings, it can be 
Table 3. Estimated mean difference in blood pressure associated with 2 SD higher intakes of total fibre, insoluble fibre and soluble fibre in US INTERMAP participants, excluding those with hypertension and users of antihypertensive drugs

(Mean differences and $95 \%$ confidence intervals; $n$ 1477)*

\begin{tabular}{|c|c|c|c|c|c|c|c|c|c|c|c|c|}
\hline \multirow[b]{3}{*}{ Model } & \multicolumn{6}{|c|}{$\mathrm{SBP}(\mathrm{mmHg})$} & \multicolumn{6}{|c|}{$\mathrm{DBP}(\mathrm{mmHg})$} \\
\hline & \multicolumn{3}{|c|}{ Not adjusted for BMI } & \multicolumn{3}{|c|}{ Adjusted for BMI } & \multicolumn{3}{|c|}{ Not adjusted for BMI } & \multicolumn{3}{|c|}{ Adjusted for BMI } \\
\hline & Difference & $95 \% \mathrm{Cl}$ & $P$ & Difference & $95 \% \mathrm{Cl}$ & $P$ & Difference & $95 \% \mathrm{Cl}$ & $P$ & Difference & $95 \% \mathrm{Cl}$ & $P$ \\
\hline \multicolumn{13}{|l|}{ Total fibre } \\
\hline Model 1 & -3.50 & $-4 \cdot 80,-2 \cdot 20$ & $<0.0001$ & -3.45 & $-4.74,-2 \cdot 16$ & $<0.0001$ & $-2 \cdot 01$ & $-2.95,-1.06$ & $<0.0001$ & -1.47 & $-2.37,-0.56$ & 0.002 \\
\hline Model 2 & $-2 \cdot 76$ & $-4.11,-1.40$ & $<0.0001$ & -1.82 & $-3.10,-0.54$ & 0.01 & -1.77 & $-2.75,-0.78$ & 0.0004 & $-1 \cdot 19$ & $-2 \cdot 13,-0.24$ & 0.01 \\
\hline Model 3 & $-2 \cdot 77$ & $-4.12,-1.43$ & $<0.0001$ & -1.85 & $-3.13,-0.57$ & 0.005 & -1.78 & $-2.75,-0.80$ & 0.0004 & $-1 \cdot 19$ & $-2.14,-0.25$ & 0.01 \\
\hline Model 4 & -3.06 & $-4.44,-1.68$ & $<0.0001$ & -2.05 & $-3.36,-0.74$ & 0.002 & -1.87 & $-2 \cdot 87,-0.87$ & 0.0003 & -1.24 & $-2 \cdot 20,-0 \cdot 27$ & 0.01 \\
\hline Model 5 & $-2 \cdot 70$ & $-4.05,-1.35$ & $<0.0001$ & -1.79 & $-3.07,-0.52$ & 0.01 & -1.73 & $-2.71,-0.76$ & 0.001 & $-1 \cdot 17$ & $-2 \cdot 11,-0.23$ & 0.02 \\
\hline Model 6 & -3.02 & $-4.43,-1.60$ & $<0.0001$ & -1.69 & $-3.04,-0.34$ & 0.014 & -1.96 & $-2.99,-0.93$ & 0.0002 & $-1 \cdot 15$ & $-2.14,-0.15$ & 0.02 \\
\hline \multirow{2}{*}{\multicolumn{13}{|c|}{ Insoluble }} \\
\hline & & & & & & & & & & & & \\
\hline Model 1 & -3.80 & $-5 \cdot 80,-1 \cdot 79$ & 0.0002 & -3.08 & $-4.98,-1 \cdot 19$ & 0.001 & $-2 \cdot 90$ & $-4 \cdot 36,-1 \cdot 45$ & $<0.0001$ & $-2 \cdot 46$ & $-3.85,-1.06$ & 0.001 \\
\hline Model 2 & $-3 \cdot 29$ & $-5 \cdot 30,-1 \cdot 28$ & 0.001 & -2.54 & $-4.44,-0.65$ & 0.01 & $-2 \cdot 60$ & $-4 \cdot 05,-1 \cdot 14$ & 0.001 & $-2 \cdot 13$ & $-3.53,-0.74$ & 0.003 \\
\hline Model 3 & $-3 \cdot 15$ & $-5 \cdot 15,-1 \cdot 15$ & 0.002 & -2.52 & $-4.42,-0.63$ & 0.01 & -2.52 & $-3.97,-1.07$ & 0.001 & $-2 \cdot 13$ & $-3.52,-0.73$ & 0.003 \\
\hline Model 4 & -3.51 & $-5.53,-1.50$ & 0.001 & $-2 \cdot 71$ & $-4.62,-0.81$ & 0.01 & -2.67 & $-4 \cdot 14,-1 \cdot 21$ & 0.0004 & $-2 \cdot 18$ & $-3.58,-0.77$ & 0.002 \\
\hline Model 5 & -3.25 & $-5.25,-1.25$ & 0.002 & -2.52 & $-4.41,-0.63$ & 0.01 & -2.57 & $-4.03,-1 \cdot 12$ & 0.001 & $-2 \cdot 12$ & $-3.52,-0.73$ & 0.003 \\
\hline Model 6 & -3.37 & $-5 \cdot 39,-1.36$ & 0.001 & $-2 \cdot 48$ & $-4.38,-0.58$ & 0.01 & $-2 \cdot 66$ & $-4 \cdot 12,-1 \cdot 20$ & 0.0004 & $-2 \cdot 11$ & $-3.51,-0.71$ & 0.003 \\
\hline \multicolumn{13}{|l|}{$\begin{array}{l}\text { Soluble } \\
\text { fibref }\end{array}$} \\
\hline Model 1 & 0.33 & $-1 \cdot 66,2 \cdot 32$ & 0.74 & 0.36 & $-1.51,2.23$ & 0.70 & 0.88 & $-0.56,2.32$ & 0.23 & 0.90 & $-0.48,2.28$ & 0.20 \\
\hline Model 2 & 0.68 & $-1 \cdot 30,2 \cdot 66$ & 0.50 & 0.79 & $-1.07,2.66$ & 0.41 & 0.82 & $-0.62,2 \cdot 26$ & 0.26 & 0.89 & $-0.49,2.26$ & 0.21 \\
\hline Model 3 & 0.48 & $-1.50,2.45$ & 0.64 & 0.74 & $-1 \cdot 13,2 \cdot 60$ & 0.44 & 0.71 & $-0.72,2 \cdot 14$ & 0.33 & 0.87 & $-0.51,2.25$ & 0.22 \\
\hline Model 4 & 0.63 & $-1 \cdot 35,2 \cdot 61$ & 0.54 & 0.75 & $-1 \cdot 11,2 \cdot 61$ & 0.43 & 0.80 & $-0.64,2.24$ & 0.27 & 0.88 & $-0.50,2.25$ & 0.21 \\
\hline Model 5 & 0.72 & $-1 \cdot 25,2 \cdot 69$ & 0.47 & 0.82 & $-1 \cdot 04,2 \cdot 68$ & 0.39 & 0.84 & $-0.59,2.27$ & 0.25 & 0.90 & $-0.47,2.28$ & 0.20 \\
\hline Model 6 & 0.55 & $-1.45,2.55$ & 0.59 & 0.89 & $-0.99,2.77$ & 0.35 & 0.71 & $-0.74,2 \cdot 16$ & 0.34 & 0.92 & $-0.47,2.31$ & 0.19 \\
\hline
\end{tabular}

DBP, diastolic blood pressure; SBP, systolic blood pressure.

* $2 \mathrm{sD}$ fibres ( $\mathrm{g} / 4184 \mathrm{~kJ}(\mathrm{~g} / 1000 \mathrm{kcal})$ ) total fibre (6.9); insoluble fibre (4.8); soluble fibre (2.2). Model 1 was adjusted for age, gender, total energy ( $\mathrm{kJ} / 24 \mathrm{~h}(\mathrm{kcal} / 24 \mathrm{~h}))$, total protein (\% energy), total fat (\% energy), total sugar (\% energy) and population sample. Model 2 was adjusted as model 1 variables plus adherence to energy-restricted diet, smoking, alcohol intake $(\mathrm{g} / 24 \mathrm{~h})$, hours engaged in moderate and heavy physical activity, dietary supplement use, educational level, CVD or diabetes diagnosis and family history of high blood pressure. Model 3 was adjusted as model 2 plus urinary $\mathrm{Na}(\mathrm{mmol} / 24 \mathrm{~h}$ ). Model 4 was adjusted as model 2 plus urinary Mg (mmol/24 h). Model $5 \mathrm{was}$ adjusted as model 2 plus urinary calcium ( $\mathrm{mmol} / 24 \mathrm{~h})$. Model 6 was adjusted as model 2 plus urinary $\mathrm{K}(\mathrm{mmol} / 24 \mathrm{~h})$.

$\dagger$ Additionally adjusted for soluble fibre ( $\mathrm{g} / 4184 \mathrm{~kJ}(\mathrm{~g} / 1000 \mathrm{kcal}))$.

$\ddagger$ Additionally adjusted for insoluble fibre $(\mathrm{g} / 4184 \mathrm{~kJ}$ (g/1000 kcal)).

posited that the inverse associations between total, insoluble fibre and BP observed in our study are independent of BMI and of nutrients associated with higher intakes of high-fibre foods, including $\mathrm{K}$.

Limitations of our study include its cross-sectional design making causal inferences not possible, regression dilution bias related to imprecise measures and the reliability estimate has been calculated to show the potential of bias (despite repeated measures), systematic bias from including multiple centres and possible residual confounding. However, extensive efforts were made to minimise these limitations (extensive observer training, repeated measurements of $\mathrm{BP}$, standardised methods in dietary collection and BP measures, open-end questions and on-going quality control). In addition, although four $24 \mathrm{~h}$ dietary recalls were made, the dietary data may not be representative of a participant's long-term habitual intake. In addition, although the associations between total, insoluble fibre intake and BP were independent of highly correlated nutrient intakes including $\mathrm{K}$, we cannot rule out that other nutrients and phytochemicals abundant in high-fibre foods may be responsible for the observed inverse fibre-BP association ${ }^{(33)}$.

In conclusion, in this cross-sectional study of free-living US participants, higher intakes of total fibre and insoluble fibre were associated with lower BP. Therefore, it may be a favourable approach to choose fibre-rich foods to prevent elevated BP. Confirmation from large-scale, prospective population studies with high-quality dietary data and BP measurements and intervention studies is, however, needed.

\section{Acknowledgements}

The authors thank all INTERMAP staff at local, national and international centres for their invaluable efforts. A partial listing of these colleagues is given in Holmes et al. ${ }^{(34)}$.

This study was supported by grants (R01-HL65461, R01HL50490 and R01-HL84228) from the National Heart, Lung and Blood Institute, National Institutes of Health and by the National Institutes of Health Office on Dietary Supplements (Bethesda, MD, USA); also by national agencies in Japan, People's Republic of China and the UK. P. E. acknowledges support from the National Institute for Health Research (NIHR) Imperial College Healthcare NHS Trust and Imperial College Biomedical Research Centre (grant number P38084), the MRC-PHE Centre for Environment and Health and the NIHR Health Protection Research Unit on Health Impact of Environmental Hazards; he is an NIHR Senior Investigator. The views expressed are those of the author and not necessarily those of the NHS, the NIHR or the UK Department of Health.

P. E. and J. S. are the principal investigators of INTERMAP and carried out the study set-up, design and methodology. G. A. carried out the writing of the paper. G. A. and L. O. G. carried out the analyses and methodology. G. F., Q. C., P. E., M. D. and 
L. V. H. were constantly involved in writing and editing the paper. All the authors were involved in writing the paper and gave their final approval for the submitted and published versions.

There are no conflicts of interest.

\section{Supplementary material}

For supplementary material/s referred to in this article, please visit http://dx.doi.org/doi:10.1017/S0007114515003098

\section{References}

1. Lim S, Vos T, Flaxman A, et al. (2012) A comparative risk assessment of burden of disease and injury attributable to 67 risk factors and risk factor clusters in 21 regions, 1990-2010: a systematic analysis for the Global Burden of Disease Study 2010. Lancet 380, 2224-2260.

2. Chen G, Lv D, Pang Z, et al. (2012) Dietary fiber intake and stroke risk: a meta-analysis of prospective cohort studies. Eur J Clin Nutr. 67, 96-100.

3. Pereira M, O'Reilly E, Augustsson K, et al. (2004) Dietary fiber and risk of coronary heart disease: a pooled analysis of cohort studies. Arch Intern Med. 164, 370-376.

4. Ascherio A. (1992) A prospective study of nutritional factors and hypertension among US men. Circulation 86 , 1475-1484.

5. Ascherio A, Hennekens C, Willett W, et al. (1996) Prospective study of nutritional factors, blood pressure, and hypertension among US women. Hypertension 27, 1065-1072.

6. Stamler J, Caggiula A \& Grandits G (1997) Relation of body mass and alcohol, nutrient, fiber, and caffeine intakes to blood pressure in the special intervention and usual care groups in the multiple risk factor intervention trial. Am J Clin Nutr. 65 , 338S-365SS.

7. He J, Klag M, Whelton P, et al. (1995) Oats and buckwheat intakes and cardiovascular disease risk factors in an ethnic minority of China. Am J Clin Nutr. 61, 366-372.

8. Masala G, Bendinelli B, Versari D, et al. (2008) Anthropometric and dietary determinants of blood pressure in over 7000 Mediterranean women: the European Prospective Investigation into Cancer and Nutrition-Florence cohort. J Hypertens 26, 2112-2120.

9. Ludwig D, Pereira M \& Kroenke C (1999) Dietary fiber, weight gain, and cardiovascular disease risk factors in young adults. JAMA 282, 1539-1546.

10. Elliott P, Fehily A, Sweetnam P, et al. (1987) Diet, alcohol, body mass, and social factors in relation to blood pressure: the Caerphilly heart study. Epidemiol Community Health 41, $37-43$.

11. Streppel M, Arends L, Van't Veer P, et al. (2005) Dietary fiber and blood pressure: a meta-analysis of randomized placebo-controlled trials. Arch Intern Med 165, 150-156.

12. Whelton S, Hyre A, Pedersen B, et al. (2005) Effect of dietary fiber intake on blood pressure: a meta-analysis of randomized, controlled clinical trials. J Hypertens 23, 475-481.

13. Birketvedt G, Aaseth J, Florholmen J, et al. (2000) Long-term effect of fibre supplement and reduced energy intake on body weight and blood lipids in overweight subjects. Acta Medica 43, 129-132.

14. Burke V, Hodgson J, Beilin L, et al. (2001) Dietary protein and soluble fiber reduce ambulatory blood pressure in treated hypertensives. Hypertension 38, 821-826.
15. Onning G, Wallmark A, Persson M, et al. (1999) Consumption of oat milk for 5 weeks lowers serum cholesterol and LDL-cholesterol in free-living men with moderate hypercholesterolemia. Ann Nutr Metab. 43, 301-309.

16. Ryttig K, Tellnes G, Haegh L, et al. (1989) A dietary fibre supplement and weight maintenance after weight reduction: a randomized, double-blind, placebo-controlled long-term trial. Int J Obes 13, 165-171.

17. Swain J, Rouse I, Curley C, et al. (1990) Comparison of the effects of oat bran and low-fiber wheat on serum lipoprotein levels and blood pressure. $N$ Engl J Med 322, 147-152.

18. Lairon D, Arnault N, Bertrais S, et al. (2005) Dietary fiber intake and risk factors for cardiovascular disease in French adults. Am J Clin Nutr 82, 1185-1194.

19. Stamler J, Elliott P, Dennis B, et al. (2003) INTERMAP: background, aims, design, methods, and descriptive statistics (nondietary). J Hum Hypertens 17, 591-608.

20. Dennis B, Stamler J, Buzzard M, et al. (2003) INTERMAP: the dietary data process and quality control. J Hum Hypertens $\mathbf{1 7}$, 609-622.

21. Schakel S, Dennis B, Wold A, et al. (2003) Enhancing data on nutrient composition of foods eaten by participants in the INTERMAP study in China, Japan, the United Kingdom, and the United States. J Food Compost Anal 16, 395-408.

22. Dyer A, Shipley M \& Elliott P (1994) Urinary electrolyte excretion in 24 hours and blood pressure in the INTERSALT study. I. Estimates of reliability. The INTERSALT cooperative research group. Am J Epidemiol 139, 927-939.

23. Willett W, Howe G \& Kushi L (1997) Adjustment for total energy intake in epidemiologic studies. Am J Clin Nutr $\mathbf{6 5}$, Suppl., 1220S-1228S.

24. Fehily A, Milbank J, Yarnell J, et al. (1982) Dietary determinants of lipoproteins, total cholesterol, viscosity, fibrinogen, and blood pressure. Am J Clin Nutr 36, 890-896.

25. Joffres M, Reed D \& Yano K (1987) Relationship of magnesium intake and other dietary factors to blood pressure: the Honolulu heart study. Am J Clin Nutr 45, 469-475.

26. Bingham S, Gill C, Welch A, et al. (1994) Comparison of dietary assessment methods in nutritional epidemiology: weighed records v. $24 \mathrm{~h}$ recalls, food-frequency questionnaires and estimated-diet records. Br J Nutr $\mathbf{7 2}$, 619-643.

27. Threapleton D, Greenwood D, Evans C, et al. (2013) Dietary fibre intake and risk of cardiovascular disease: systematic review and meta-analysis. BMJ 347, f6879.

28. Brock D, Davis C, Irving B, et al. (2006) A high-carbohydrate, high-fiber meal improves endothelial function in adults with the metabolic syndrome. Diabetes Care 29, 2313-2315.

29. Pal S, Khossousi A, Binns C, et al. (2012) The effects of 12-week psyllium fibre supplementation or healthy diet on blood pressure and arterial stiffness in overweight and obese individuals. Br J Nutr 107, 725-734.

30. Kelly SA, Summerbell CD, Brynes A, et al. (2007) Wholegrain cereals for coronary heart disease. Cochrane Database Syst Rev 2, Cd005051.

31. Chandalia M, Garg A, Lutjohann D, et al. (2000) Beneficial effects of high dietary fiber intake in patients with type 2 diabetes mellitus. N Engl J Med 342, 1392-1398.

32. Anderson JW, Baird P, Davis RH Jr, et al. (2009) Health benefits of dietary fiber. Nutr Rev 67, 188-205.

33. Hooper L, Kroon PA, Rimm EB, et al. (2008) Flavonoids, flavonoid-rich foods, and cardiovascular risk: a meta-analysis of randomized controlled trials. Am J Clin Nutr. 88, 38-50.

34. Holmes E, Loo R, Stamler J, et al. (2008) Human metabolic phenotype diversity and its association with diet and blood pressure. Nature 453, 396-400. 